\title{
HUBUNGAN KUALITAS PELAYANAN KESEHATAN RAWAT JALAN DENGAN TINGKAT KEPUASAN PASIEN PESERTA JAMINAN KESEHATAN NASIONAL DI RSU MUHAMMADIYAH SUMATERA UTARA
}

\author{
Relationship of Outpatients Quality Health services with The \\ Satisfaction of Patients National Health Insurance in \\ Muhammadiyah Hospital North Sumatera \\ Hasbina Wildani ${ }^{1}$, Muhammad Badiran ${ }^{2}$, Anto J. Hadi ${ }^{2}$ \\ 1 Universitas Muhammadiyah Sumatera Utara \\ 2 Institut Kesehatan Helvetia Medan \\ hasbinawildani@gmail.com
}

\begin{abstract}
ABSTRAK
Pelayanan rumah sakit menyediakan jasa yang dijual kepada pelanggan. Kunjungan pasien rawat jalan di RSU Muhammadiyah Sumatera Utara mengalami kenaikan tetapi tidak membuat mereka serta merta merasa puas dengan rumah sakit. Penelitian ini bertujuan untuk mengetahui hubungan kualitas pelayanan dengan kepuasan pasien rawat jalan peserta JKN di RSU Muhammadiyah Sumatera Utara. Jenis penelitian adalah cross sectional dengan sampel 75 responden dan pengambilan sampel secara accidental sampling. Metode analisis data yang digunakan adalah chi square dan uji regresi logistik. Hasil penelitian menunjukkan bahwa faktor yang berhubungan dengan kepuasan pasien rawat jalan adalah tanglibility $(p=0,016)$, reliability $(p=0,021)$, responsiveness $(p=0,001)$, assurance $(p=$ $0,001)$, dan empathy $(p=0,001)$. Kesimpulan diperoleh bahwa adalah ada hubungan tanglibility, reliability, responsiveness, assurance dan empathy dengan kepuasan pasien rawat jalan. Diharapkan bagi rumah sakit untuk mempertahan pelanggan dan menambah jumlah kunjungan yaitu dengan meningkatkan kualitas pelayanan dan melengkapi prasarana yang masih kurang, sehingga kepuasan pasien terpenuhi dan pasien menjadi loyal.
\end{abstract}

\section{Kata Kunci: Kualitas Pelayanan, Kepuasan, Rawat Jalan}

\begin{abstract}
Hospital services provide services that are sold to customers. Outpatient visits at Muhammadiyah General Hospital in North Sumatra have increased but it does not necessarily make them feel satisfied with the hospital. This study aims to determine the relationship of service quality with the satisfaction of JKN outpatients in North Sumatra Muhammadiyah Hospital. This type of research is cross sectional with a sample of 75 respondents and sampling by accidental sampling. Data analysis methods used were chi square and logistic regression tests. The results showed that
\end{abstract}


the factors associated with outpatient satisfaction were tanglibility $(p=0.016)$, reliability $(p=0.021)$, responsiveness $(p=0.001)$, assurance $(p=0.001)$, and empathy $(p=0.001)$. The conclusion is that there is a correlation between tangibility, reliability, responsiveness, assurance and empathy with outpatient satisfaction. It is expected for hospitals to retain customers and increase the number of visits, namely by improving the quality of service and completing infrastructure that is still lacking, so that patient satisfaction is fulfilled and patients become loyal.

\section{Keywords: Service Quality, Satisfaction, Outpatient}

\section{PENDAHULUAN}

Rumah sakit dituntut untuk memberikan mutu pelayanan yang berkualitas, dan mampu memenuhi harapan pasien. Tuntutan terhadap mutu selalu berubahubah dan makin tinggi, sesuai dengan kebutuhan pasien. Pelayanan yang berkualitas dapat mempertahankan dan menumbuhkan rasa kepuasan pasien terhadap suatu rumah sakit (Istiqna, 2015). Kepuasan pelanggan memiliki hubungan yang erat dengan kualitas. Kualitas memberikan suatu dorongan kepada pelanggan untuk menjalin ikatan hubungan yang kuat dengan perusahaan(Fahrepi, Rate, \& Hadi, 2019). Dalam jangka panjang, ikatan seperti ini memungkinkan perusahaan untuk memahami dengan seksama harapan dan kebutuhan pelanggan. Dengan demikian perusahaan dapat meningkatkan kepuasan pelanggan dengan cara memaksimumkan pengalaman yang menyenangkan dan meminimumkan atau meniadakan pengalaman pelanggan yang kurang menyenangkan (Tjiptono, 2006).

Pelayanan kesehatan bermutu yaitu yang memenuhi kebutuhan dan keinginan pasien agar pasien merasa puas terhadap pelayanan yang diberikan oleh rumah sakit dengan melakukan pelayanan prima. Melalui pelayanan prima, rumah sakit diharapkan akan menghasilkan keunggulan kompetitif (competitive advantage) dengan pelayanan bermutu dan efisien (Departemen Kesehatan Rl. UndangUndang Republik Indonesia Nomor 36 Tahun 2009 Tentang Kesehatan. Jakarta: Kementrian Kesehatan RI: 2009., 2009). Harapan pasien dapat dilihat melalui indikator kualitas pelayanan kesehatan yang diberikan rumah sakit sebagai provider. Persepsi pasien terhadap kualitas pelayanan berlanjut pada proses terbentuknya persepsi secara umum terhadap rumah sakit. Persepsi pasien tentang kualitas pelayanan merupakan penilaian menyeluruh atas keunggulan suatu jasa atau pelayanan, sehingga kepuasan pasien dapat dilihat berdasarkan persepsinya atas kualitas pelayanan yang diberikan ketika memanfaatkan rumah sakit (Tjiptono, 2006). Dari service quality dapat diketahui dengan cara membandingkan persepsi para pelanggan atas pelayanan yang nyata-nyata mereka terima atau peroleh dengan pelayanan yang sesungguhnya mereka harapkan dan inginkan. Jika kenyataan lebih besar dari yang diharapkan, maka pelayanan dapat dikatakan 
bermutu, sedangkan jika kenyataan kurang dari yang diinginkan, maka pelayanan dapat dinyatakan kurang bermutu, apabila kenyataan sama dengan harapan, maka pelayanan disebut memuaskan.

Di Indonesia, terkait dengan kualitas pelayanan Puskesmas di era pelaksanaan JKN, hasil evaluasi Dewan Jaminan Sosial Nasional (DJSN) yang dilakukan pada bulan September 2014, menunjukan belum berjalan secara baik mekanisme rujukan, belum memadai kapasitas fasilitas kesehatan primer, belum optimal pelayanan kepada peserta, dan belum lengkap e-katalog 2014. Bagi peserta sebagian besar merasakan kurang puas akan pelayanan, seperti hak peserta Askes dan Jamsostek dikurangi terkait berbedanya obat yang dapat diklaim dari Jamsostek ke BPJS (Keputusan Ketua Dewan Jaminan Sosial Nasional, 2014) .

Paradigma baru pelayanan kesehatan mensyaratkan rumah sakit memberikan pelayanan yang prima. Salah satu syarat utama agar rumah sakit dapat bertahan hidup adalah bila mampu memberi pelayanan prima pada pelanggannya sesuai kebutuhan dan keinginan pasien dengan tetap mengacu kode etik profesi dan medis, sehingga rumah sakit dituntut untuk melakukan pelayanan prima sesuai dengan harapan pasien (Aditama, 2010). Peran tenaga medis dalam memberikan pelayanan kesehatan di rumah sakit menjadi sangat penting, karena kinerja petugas kesehatan secara organisasi akan menentukan persepsi pasien terhadap kualitas pelayanan yang diberikan dan kepuasan atas pelayanan yang diterima. Pasien akan selalu membandingkan atau meminta rekomendasi orang lain dalam pemanfaatan sarana pelayanan kesehatan. Kualitas pelayanan pada industri yang bergerak di sektor jasa menurut Parasuraman et al. (2003) dapat dievaluasi dengan menggunakan metode SERVQUAL (Service Quality). Dimensi yang dilihat pada kualitas layanan antara lain dimensi keandalan (reliability), ketanggapan (responsiveness), jaminan (assurance), empati (empathy), dan penampilan(tangible) (Aditama, 2010).

Rumah Sakit Umum Muhammadiyah Sumatera Utara adalah rumah sakit tipe D. Dimana jumlah bed (tempat tidur) keseluruhan berjumlah 36 unit. Salah satu unit pelayanannya adalah poliklinik rawat jalan. Untuk pelayanan rawat jalan, Rumah Sakit Umum Muhammadiyah Sumatera Utara melakukan pelayanan pada jenis pelayanan. Jumlah kunjungan pasien rawat jalan peserta JKN selama 1 tahun terakhir berkisar 3.588 pasien. Dan mengalami kemunduran jumlah pasien pada pertengahan tahun lalu. Untuk saat ini kedaan rumah sakit dalam pembenahan baik dari infrastuktur maupun manajemen rumah sakit nya. Survei awal dilakukan melalui wawancara terhadap 7 orang pasien rawat jalan peserta JKN yang baru pertama kali berkunjung ke RSU Muhammadiyah Medan, ditemukan sebanyak 6 orang mengeluhkan pelayanan kesehatan yang diberikan dokter dan perawat belum sesuai 
dengan yang diharapkan. Pelayanan yang dirasakan kurang baik antara lain: kepedulian tenaga kesehatan, jadwal kunjungan dokter spesialis yang tidak tepat waktu, keramahan perawat, fasilitas yang kurang memadai. Artinya $85 \%$ pasien mengeluhkan rasa kurang puas terhadap pelayanan yang dirasakannya saat di Rumah Sakit Umum Muhammadiyah Sumatera Utara. Wawancara dengan pihak manajemen Rumah Sakit Umum Muhammadiyah sampai saat ini pihak rumah sakit belum pernah melakukan pengukuran kepuasan pasien terhadap pelayanan rawat jalan sebagai upaya dasar untuk menentukan strategi pelayanan yang lebih lanjut. Mengingat pemanfaatan rumah sakit dalam era JKN semakin terbuka lebar dan atas dasar fenomena yang telah diuraikan diatas maka peneliti tertarik melakukan penelitian bertujuan untuk mengetahui hubungan pelayanan rawat jalan berdasarkan 5 dimensi yaitu kehandalan (reliability), daya tanggap (responsiveness), jaminan (assurance), empati (empathy), dan prasarana (tangibles) dengan tingkat kepuasan pasien rawat jalan peserta JKN di Rumah Sakit Umum Muhammadiyah Sumatera Utara.

Akses terhadap layanan kesehatan pada Rumah Sakit dalam era JKN semakin terbuka lebar. Penyelenggaraan program JKN oleh BPJS kesehatan di Rumah Sakit Muhammadiyah Mandala Sumut telah berjalan kurang lebih 3 tahun, yaitu tepatnya dimulai dibulan September 2016. Jumlah kunjungan pasien rawat jalan peserta JKN selama 1 tahun terakhir berkisar 3588 pasien. Dan mengalami kemunduran jumlah pasien pada pertengahan tahun lalu. Untuk saat ini kedaan rumah sakit dalam pembenahan baik dari infrastuktur maupun manajemen rumah sakit nya. Penelitian ini bertujuan untuk menganalisis hubungan kualitas pelayanan Kesehatan Rawat Jalan (tanglibility, reliability, responsiveness, assurance dan empathy) dengan Tingkat Kepuasan Pasien Peserta Jaminan Kesehatan Nasional di Rumah Sakit Umum Muhammadiyah Sumatera Utara.

\section{BAHAN DAN METODE}

Penelitian ini menggunakan desain cross-sectional study. Penelitian ini dilakukan di Unit Rawat Jalan Rumah Sakit Umum Muhammadiyah Sumatera Utara Jalan Mandala By Pass No. 27 Medan, dari bulan Oktober Tahun 2019. Populasi adalah seluruh pasien rawat jalan peserta JKN tahun 2019 meliputi Poli Anak, Poli Obgyn, Poli Penyakit Dalam dan Poli Bedah berjumlah 3588 orang (rata-rata 299 pasien per bulan), maka jumlah sampel yang dibutuhkan untuk penelitian ini adalah 75 orang.Teknik pengambilan sampel pada penelitian ini adalah accidental sampling. Analisis data dilakukan secara univariat, bivariat dan multivariat. 
HASIL

Tabel 1. Distribusi Karakteristik Responden di Rumah Sakit Umum Muhammadiyah Sumatera Utara

\begin{tabular}{lrr}
\hline \multicolumn{1}{c}{ Karakteristik Responden } & \multicolumn{2}{c}{ Jumlah } \\
\cline { 2 - 3 } & $\mathbf{n}$ & $\%$ \\
\hline $16-25$ tahun & 15 & 20,0 \\
$26-35$ tahun & 26 & 34,7 \\
$36-45$ tahun & 8 & 10,7 \\
$46-55$ tahun & 13 & 17,3 \\
$56-65$ tahun & 9 & 12,0 \\
$66-75$ tahun & 4 & 5,3 \\
\hline Laki - laki & 6 & 8,0 \\
Perempuan & 69 & 92,0 \\
& & \\
SD & 13 & 17,3 \\
SLTP & 10 & 13,3 \\
SLTA & 39 & 52,0 \\
Diploma & 8 & 10,7 \\
Sarjana & 5 & 6,7 \\
Tidak Bekerja & 32 & 42,7 \\
Wiraswasta & 17 & 22,7 \\
Petani & 12 & 16,0 \\
IRT & 8 & 10,7 \\
PNS/TNI/POLRI & 6 & 8,0 \\
\hline
\end{tabular}

Berdasarkan tabel 1 dapat dilihat hasil penelitian menunjukkan bahwa sebagian besar responden berumur 26 s/d 35 tahun sebanyak 26 orang $(34,7 \%)$, dan minoritas responden berusia 66 - 75 tahun sebanyak 4 orang $(5,3 \%)$, berjenis kelamin perempuan sebanyak 69 orang (92\%), dan responden berjenis kelamin lakilaki sebanyak 6 orang (8\%), berpendidikan SLTA sebanyak 39 orang (52\%) dan minoritas responden berpendidikan Sarjana sebanyak 5 orang $(6,7 \%)$, tidak bekerja sebanyak 32 orang $(42,7 \%)$, dan minoritas bekerja sebagai PNS/TNI/POLRI sebanyak 6 (8\%).

Tabel 2. Hubungan Kualitas Pelayanan Kesehatan dengan 
Kepuasan Pasien di RSU Muhammadiyah Sumatera

Utara

\begin{tabular}{|c|c|c|c|c|c|c|c|}
\hline \multirow{3}{*}{$\begin{array}{l}\text { Kualitas } \\
\text { Pelayanan } \\
\text { Kesehatan }\end{array}$} & \multicolumn{4}{|c|}{$\begin{array}{c}\text { Kepuasan Pasien } \\
\text { Rawat Jalan Peserta } \\
\text { JKN }\end{array}$} & & & \multirow{3}{*}{$p$-value } \\
\hline & \multicolumn{2}{|c|}{ Puas } & \multicolumn{2}{|c|}{$\begin{array}{l}\text { Tidak } \\
\text { Puas }\end{array}$} & \multicolumn{2}{|c|}{ Jumlah } & \\
\hline & $\mathrm{n}$ & $\%$ & $\mathrm{n}$ & $\%$ & $\mathrm{n}$ & $\%$ & \\
\hline \multicolumn{8}{|l|}{ Tanglibility } \\
\hline Baik & 43 & 57,3 & 9 & 12,0 & 52 & 69,3 & 0,016 \\
\hline Tidak Baik & 13 & 17,3 & 10 & 13,3 & 23 & 30,7 & \\
\hline \multicolumn{8}{|l|}{ Reliability } \\
\hline Baik & 44 & 58,7 & 19 & 25,3 & 63 & 84,0 & 0,021 \\
\hline Tidak Baik & 12 & 16,0 & 0 & 0 & 12 & 16,0 & \\
\hline \multicolumn{8}{|c|}{ Responsiveness } \\
\hline Baik & 33 & 44,0 & 3 & 4,0 & 36 & 48,0 & 0,001 \\
\hline Tidak Baik & 23 & 30,7 & 16 & 21,3 & 39 & 52,0 & \\
\hline \multicolumn{8}{|l|}{ Assurance } \\
\hline Baik & 41 & 54,7 & 6 & 8,0 & 47 & 62,7 & 0,001 \\
\hline Tidak Baik & 15 & 20,0 & 13 & 17,3 & 28 & 37,3 & \\
\hline \multicolumn{8}{|l|}{ Empathy } \\
\hline Baik & 38 & 48,0 & 4 & 5,3 & 40 & 53,3 & 0,001 \\
\hline Tidak Baik & 20 & 26,7 & 15 & 20,0 & 35 & 46,7 & \\
\hline
\end{tabular}

Berdasarkan tabel 2 tabulasi silang antara tanglibility dengan kepuasan pasien rawat jalan peserta JKN diketahui bahwa dari 52 responden yang menyatakan kualitas pelayanan (tanglibility) dalam kategori baik, 43 (57,3\%) menyatakan puas dengan pelayanan dan $9(12 \%)$ menyatakan tidak puas dengan pelayanan di RSU Muhammadiyah Sumatera Utara. Sedangkan dari 23 responden yang menyatakan tanglibility pelayanan dalam kategori tidak baik, 13 (17,3\%) menyatakan puas dan $10(13,3 \%)$ menyatakan tidak puas dengan pelayanan di Unit Rawat Jalan RSU Muhammadiyah Sumatera Utara. Hasil uji bivariat menggunakan Chi-Square diperoleh nilai $p=0,016<0,05$, terbukti Ho ditolak sehingga dapat disimpulkan terdapat hubungan yang signifikan antara tanglibility dengankepuasan pasien Unit Rawat Jalan Peserta JKN di RSU Muhammadiyah, reliability dengan kepuasan pasien rawat jalan peserta JKN diketahui bahwa dari 63 responden yang menyatakan kualitas pelayanan (tanglibility) dalam kategori baik, 44 (58.7\%) menyatakan puas dengan pelayanan dan 19 (25,3\%) menyatakan tidak puas dengan pelayanan di RSU Muhammadiyah Sumatera Utara. Sedangkan dari 12 responden yang menyatakan reliability pelayanan dalam kategori tidak baik, seluruhnya atau 12 (16\%) menyatakan puas dengan pelayanan di Unit Rawat Jalan RSU Muhammadiyah Sumatera Utara. Hasil uji bivariat menggunakan Chi-Square 
diperoleh nilai $p=0,021(p<0,05)$, terbukti Ho ditolak sehingga dapat disimpulkan terdapat hubungan yang signifikan antara reliability dengan kepuasan pasien Unit Rawat Jalan Peserta JKN di RSU Muhammadiyah Sumatera Utara, resvonsiveness dengan kepuasan pasien rawat jalan peserta JKN diketahui bahwa dari 39 responden yang menyatakan resvonsiveness pelayanan dalam kategori tidak baik, $23(30,7 \%)$ menyatakan puas dan $16(21,3 \%)$ menyatakan tidak puas dengan pelayanan di Unit Rawat Jalan RSU Muhammadiyah Sumatera Utara. Sedangkan dari 48 responden yang menyatakan kualitas pelayanan (resvonsiveness) dalam kategori baik, 33 (44\%) menyatakan puas dengan pelayanan dan 3 (4\%) menyatakan tidak puas dengan pelayanan di RSU Muhammadiyah Sumatera Utara. Hasil uji bivariat menggunakan Chi-Square diperoleh nilai $p=0,001 \quad(p<0,05)$, terbukti Ho ditolak sehingga dapat disimpulkan terdapat hubungan yang signifikan antara resvonsivenessdengan kepuasan pasien Unit Rawat Jalan Peserta JKN di RSU Muhammadiyah Sumatera Utara, assurance dengan kepuasan pasien rawat jalan peserta JKN diketahui bahwa dari 47 responden yang menyatakan kualitas pelayanan (assurance) dalam kategori baik, 41(54.7\%) menyatakan puas dengan pelayanan dan 6 (8\%) menyatakan tidak puas dengan pelayanan di RSU Muhammadiyah Sumatera Utara. Selanjutnya dari 28 responden yang menyatakan reliability pelayanan dalam kategori tidak baik, 15 (20\%) menyatakan puas dengan pelayanan dan $13(17,3 \%)$ menyatakan tidak puas dengan pelayanan di Unit Rawat Jalan RSU Muhammadiyah Sumatera Utara. Hasil uji bivariat menggunakan ChiSquare diperoleh nilai $p=0,001(p<0,05)$, terbukti Ho ditolak sehingga dapat disimpulkan terdapat hubungan yang signifikan antara assurancedengan kepuasan pasien Unit Rawat Jalan Peserta JKN di RSU Muhammadiyah Sumatera Utara, empathy dengan kepuasan pasien rawat jalan peserta JKN diketahui bahwa dari 40 responden yang menyatakan kualitas pelayanan (empathy) dalam kategori baik, 38 (48\%) menyatakan puas dengan pelayanan dan 4 (5,3\%) menyatakan tidak puas dengan pelayanan di RSU Muhammadiyah Sumatera Utara. Sedangkan dari 35 responden yang menyatakan empathy pelayanan dalam kategori tidak baik, 20 $(26,7 \%)$ menyatakan puas dan $15(20 \%)$ menyatakan tidak puas dengan pelayanan di Unit Rawat Jalan RSU Muhammadiyah Sumatera Utara. Hasil uji bivariat menggunakan Chi-Square diperoleh nilai $p=0,001(p<0,05)$, terbukti Ho ditolak sehingga dapat disimpulkan terdapat hubungan yang signifikan antara empathy dengan kepuasan pasien Unit Rawat Jalan Peserta JKN di RSU Muhammadiyah Sumatera Utara.

Tabel 3. Hasil Analisis Uji Regresi Logistik 


\begin{tabular}{llccl}
\hline \multicolumn{1}{c}{ Variabel } & P & B & Exp(B) & \multicolumn{1}{c}{$\mathbf{9 5 \%} \mathbf{C l}$} \\
\hline Resvonsiveness & 0,021 & 1,768 & 5,859 & $1,303-26,349$ \\
Assurance & $0,005^{*}$ & 1,914 & 6,781 & $01,787-25,729$ \\
Empathy & 0,017 & 1,723 & 5,600 & $1,367-22,934$ \\
Constant & 0,016 & $-4,159$ & & \\
\hline
\end{tabular}

Berdasarkan hasil analisis uji regresi logistik tahap dua, maka didapat variabel yang paling berpengaruh adalah variabel assurance.

\section{PEMBAHASAN}

Beberapa karakteristik kualitas pelayanan menurut Bayu dkk sebagai berikut: ketepatan waktu pelayanan, aksebilitas dan kemudahan untuk mendapatkan jasa, akurasi pendampingan/pelayanan jasa yang diberikan, sikap sopan santun karyawan yang memberikan pelayanan, kecukupan informasi yang diseminasikan kepada pengguna potensial, kondisi dan keamanan fasilitas yang digunakan oleh konsumen, kepuasan konsumen terhadap karakteristik atau aspek-aspek tertentu dari jasa publik yang diberikan, kepuasan konsumen terhadap jasa publik secara keseluruhan (Wicaksono, Setyanto, \& Oktavianty, 2003). Hasil penelitian ini sejalan dengan penelitian yang dilakukan Warwuru, tentang faktor-faktor yang berhubungan dengan loyalitas pelanggan di Instalasi Rawat Jalan di RSUP Prof. Dr. R.D. Kandou Manado. 2018, hasil penilaian tentang bukti fisik menunjukkan $67,7 \%$ yang pada umumnya berada dalam kategori baik. Bukti fisik dinilai baik karena tata letak rumah sakit mudah ditemukan oleh responden, pelayanan yang diberikan cukup memuaskan, suasana (suhu, kebisingan) cukup nyaman. Tersedia fasilitas seperti tempat sampah, kursi tunggu dan mesin ATM yang cukup memadai.

Menurut penelitian Solichah, tentang kualitas pelayanan kepuasan pasien Rumah Sakit Sarila Husada Sragen pada pasien rawat jalan tahun 2017. Hasil uji regresi berganda menunjukkan tidak sesuai dengan penelitian yang dilakukan. Dimana variabel tanglibility disimpulkan tidak berpengaruh dengan kepuasan pasien rumah sakit Sarila Husada Sragen pada pasien rawat jalan dengan $(p=0,88)$. Hal ini dapat diartikan jika perlengkapan sarana dan prasarana meningkat maka kepuasan pasien rumah sakit Sarila Husada Sragen pada pasien Rawat Jalan belum tentu akan meningkat pula (Supartiningsih, 2017). Secara keseluruhan tampilan fisik Unit Rawat Jalan RSU. Muhammadiyah Sumatera Utara sudah baik, hal ini dapat dilihat dari distribusi jawaban responden yang mengatakan rungan poli sudah bersih dan rapi, penampilan dokter dan perawat bersih dan rapi, dan pencahayaan juga sudah cukup. Akan tetapi masih ada beberapa responden yang merasa tidak puas dengan pelayanan rumah sakit, hal ini dilihat dari jawaban responden banyak yang menjawab tidak baik seperti pertanyaan sarana prasarana yang tersedia lengkap sesuai kebutuhan pasien, dan pasien juga mengeluhkan rumah sakit belum memiliki ruang tunggu yang cukup, nyaman, WC dan air.

Kondisi sekarang RS dalam pembangunan yang mengakibatkan pasien dan keluarga yang berkunjung ke Unit Rawat Jalan mengalami kebisingan dan tinggi untuk terpapar debu, listrik dan air sering mati karena keperluan renovasi. Rumah sakit dalam masa pembangunan dan sudah sewajarnya rumah sakit tampak beserak 
dengan adanya tumpukan - tumpukan pasir, pasien juga mengatakan adanya bising yang sangat tinggi disebabkan pemboran dinding untuk perbaikan instalasi listrik. Fasilitas laboratorium dan penunjang seperti radiologi juga belum ada sehingga anjuran foto dari dokter harus dilakukan di tempat lain, sedangkan syarat penggunaan JKN harus mengambil rujukan dari Fasilitas Kesehatan Tingkat I terlebih dahulu setiap akan di rujuk dan sistem ini membuat pasien mengeluhkan kerepotan. Untuk itu pembangunan diharapkan cepat selesai dan rumah sakit akan tampil dengan indahnya dengan petugas yang terampil dan ramah.

Menurut asumsi peneliti, untuk menciptakan perilaku pelanggan yang loyal di Unit Rawat Jalan RSU Muhammadiyah Sumatera Utara harus dijaga dan ditingkatkan kualitas pelayanan karena akan menimbulkan kepuasan pasien terutama peserta JKN. Pasien mengharapkan pembangunan rumah sakit secepatnya selesai, bisa melayani semua pasien yang datang berkunjung dengan sarana perasarana yang sudah lengkap. Mengacu pada hasil uji tersebut dapat dijelaskan semakin baik kualitas pelayanan reliability atau kehandalan yang diberikan RS maka akan lebih tinggi kemungkinan kepuasan pasien dan keluarga pengunjung rawat jalan peserta JKN. Menururt Gronroos dan Parasuraman, kualiatas pelayanan dibedakan menjadi dua yaitu kualitas teknikal dan kualitas fungsional. Kualitas teknikal merujuk pada kompetensi penyedia jasa untuk memberikan informasi yang dapat dipercaya dengan tingkat resiko yang dapat diterima sehingga membantu pelanggan untuk mencapai tujuannya. Pada penelitian ini harapan pelanggan terpenuhi terhadap kualitas teknikal maka mereka akan memiliki persepsi yang lebih besar terhadap kualitas teknikal. Penelitian ini sejalan dengan penelitian yang dilakukan Aminuddin, tentang hubungan antara kualitas pelayanan kesehatan dengan tingkat kepuasan pasien peserta jaminan kesehatan di Puskesmas Siko Ternate. Hasil penelitian memperlihatkan bahwa terdapat hubungan yang bermakna antara kehandalan (reliability) petugas dengan tingkat kepuasan pasien peserta JKN di Puskesmas Siko Ternate (Muhammad, 2015).

Pada penelitian Mardikanto, tentang analisis kepuasan pelanggan dengan metoda SERVQUAL di Rumah Sakit Condong Catur Yogyakarta tahun 2016 menunjukkan bahwa secara keseluruhan kepuasan pasien di RSCC dinilai rendah, dengan adanya nilai yang negatif. Semakin negatif skor Servqual maka gap yang terjadi di mata pasien semakin serius. Rendahnya kepuasan pelanggan tersebut terdapat pada dimensi, yaitu tentang kurangnya kemampuan RSCC untuk melaksanakan jasa yang dijanjikan kepada pasien dengan segera, akurat, baik, cermat, dan cepat. Hasil perhitungan gap ini menunjukkan gap antara jasa yang dirasakan/dipersepsikan oleh pelanggan lebih rendah dari pada jasa yang diharapkan pasien. Jika harapan pelanggan lebih besar daripada kenyataan yang diterima, maka kualitas jasa yang diterima kurang memuaskan, dan timbullah ketidak puasan pelanggan (Mardikanto \& Dkk, 2016) .

Berdasarkan hasil penelitian menunjukkan bahwa pasien atau masyarakat mengakui pelayanan kesehatan yang bermutu sebagai suatu layanan kesehatan yang dapat memenuhi kebutuhan yang dirasakannya dan diselenggarakan dengan cara yang sopan santun, tepat waktu, tanggap dan mampu menyembuhkan keluhannya serta mencegah berkembangnya atau meluasnya penyakit. Hal ini sangat penting karena pasien yang merasa puas akan mematuhi pengobatan dan 
mau datang berobat kembali dan menjadi pelanggan tetap rumah sakit. Fenomena ini dapat dilihat ketika petugas yang ada di Unit Rawat Jalan semuanya baik dan ramah, menerima pasien secara cepat dan tidak berbelit-belit. Pasien juga menyampaikan dokter datang tepat waktu terutama Poli Obgyn dan Poli Bedah, Dokter dan perawat juga terampil dan siap melayani pasien. Menurut asumsi peneliti, ini membuktikan bahwa reliability (kehandalan) seluruh petugas terutama petugas kesehatan dapat membuat pasien merasa puas. Karena kepuasan pasien menjadi tolak ukur tingkat kualitas pelayanan kesehatan. Pasien mengatakan akan tetap menggunakan RSU Muhammadiyah Sumut sebagai fasilitas kesehatan pertama jika pasien atau keluarga membutuhkan pelayanan kesehatan. Menurut Rust ada tiga macam karakteristik harapan seorang pelanggan. Pertama, will expectation yaitu suatu kinerja yang diperkirakan dapat diterimanya dengan semua informasi yang di dapat. Kedua, should expectation, yaitu tingkat kinerja yang dianggap sudah sepantasnya diterima pelanggan. Ketiga, ideal expectation, yaitu tigkat kinerja optimal atau terbaik yang diharapkan dapat diterima pelanggan. Dapat disimpulkan bahwa kualitas pelayanan adalah suatu upaya pemenuhan kebutuhan pelanggan disertai dengan cara penyampaian yang tepat agar kebutuhan pelanggan terpenuhi. Setiap orang mengharapkan pelayanan yang unggul, yaitu suatu sikap atau cara pegawai dalam melayani pelanggan secara memuaskan.

Hasil penelitian ini sesuai dengan penelitian yang dilakukan Sri Siswati, tentang kualitas pelayanan kesehatan dengan kepuasan pasien BPJS di Unit Rawat Inap RSUD Kota Makassar tahun 2015. Hasil penelitian diketahui bahwa terdapat pengaruh antara responsiveness $(\mathrm{p}=0,001)$ dengan kepuasan pasien BPJS di Unit Rawat Inap RSUD Kota Makassar, dan tidak ada hubungan antara jumlah personel dan ketersediaan obat dengan kepuasan pasien (Siswati, 2015). Berdasarkan hasil wawancara peneliti, variabel responsiveness ditemukan kemampuan dokter dan perawat untuk cepat tanggap menyelesaikan keluhan pasien sudan baik, tindakan petugas juga sudah cepat saat dibutuhkan. Akan tetapi masih banyak juga ditemukan responden yang merasa tidak puas dengan pelayanan berdasarkan responsiveness (ketanggapan). Responden menyampaikan dokter dalam menjelaskan penyakitnya tidak memuaskan dan susah di pahami. Terlalu singkat waktu untuk konsultasi, dokter hanya menjawab sesuai pertanyaan kita terutama Poli Penyakit Dalam. Sementara secara spesifik adanya peranan pelayanan yang diberikan secara nyata akan memberikan pengaruh bagi semua pihak terhadap manfaat yang dirasakan pelanggan.

Menurut asumsi peneliti, responsiveness berhubungan dengan kepuasan pasien rawat jalan peserta JKN karena responden yang tidak puas dengan kualitas pelayanan di Unit Rawat Jalan akan menjadi masalah untuk institusi tersebut dalam memikat hati pasien untuk tetap loyal dan menjadi pelanggan rutin rumah sakit. Dari hasil observasi responsiveness atau ketanggapan dokter dan perawat sudah baik di Unit Rawat Jalan RSU Muhammadiyah Sumatera Utara sudah baik. Kemungkinan perasaan tidak puas yang dialami pasien rawat jalan dipengaruhi faktor umur karena sebagian responden berada pada kategori usia di atas 50 tahun. Hasil penelitian ini sejalan dengan penelitian yang dilakukan Pendrita, tentang hubungan antara kualitas pelayanan dengan tingkat kepuasan pasien rawat jalan pengguna BPJS di RSI G Kabupaten Malang. Dengan menggunakan uji spearman rank hasil 
menunjukkan signifikansi output $\rho=0.03 \leq \alpha 0.05$ dan koefisien korelasi sebesar 1.00 yang berarti terdapat hubungan yang signifikan (bermakna) antara kualitas pelayanan kesehatan dengan tingkat kepuasan pasien di RSI G Kabupaten Malang (jennnie Kristina, 2017). Berdasarkan hasil wawancara variabel assurance sudah baik, hal ini dapat dilihat dari distribusi jawaban responden dari pertanyaan di RSU Muhammadiyah Sumatera Utara ketersediaan dokter spesialis baik dan sesuai untuk RS tipe $D$, perawat yang bertugas tampak terampil untuk melayani pasien, ruangan poli terpisah sesuai bidangnya dan dipanggil satu-satu jadi tidak perlu malu ke pasien lainnya.

Menurut asumsi peneliti, assurance (jaminan) pelayanan di RSU Muhammadiyah Sumatera Utara sudah baik. Baik atau buruknya kualitas RSU Muhammadiyah Sumatera Utara tergantung kepada kemampuan rumah sakit dalam memenuhi harapan pasien dan keluarga secara konsisten. Bahwa citra kualitas yang baik bukanlah berdasarkan sudut pandang RSU Muhammadiyah Sumatera Utara tetapi harus dilihat dari sudut pandang atau persepsi seluruh pengunjung. Disarankan bagi pihak rumah sakit untuk terus meningkatkan kualitas pelayanan yang ada untuk mencapai kepuasan pasien yang lebih maksimal. Hasil penelitian ini sejalan dengan penelitian Nurheda, tentang hubungan kualitas pelayanan kesehatan dengan kepuasan pasien pengguna badan penyelenggara jaminan social (BPJS) di Puskesmas Maiwaka Kabupaten Enrekang. Hasil penelitian menunjukkan bahwa adanya hubungan antara kualitas pelayanan kesehatan dengan kepuasan pasien BPJS dimana variabel empathy pelayanan $(p=0,007)$ (Rusman, 2018). Para ahli Gronroos, Sharma dan Patterson, menegaskan bahwa kualitas fungsional dihubungkan dengan interaksi antara penyedia jasa dan penerima jasa itu, dan dinilai dalam hal yang sangat subyektif. Hal ini dilihat sebagai suatu hal yang kritis untuk persepsi pelanggan dari kualitas pelayanan secara keseluruhan. Khususnya ketika banyak perusahaan jasa sulit untuk membedakan dirinya sendiri hanya pada pelayanan inti kemudian menjadi komoditas saat persaingan meningkat dan industri menjadi dewasa, maka dimensi kualitas fungsional menjadi semakin penting sebagai alat menciptakan keuntungan kompetitif yang dapat didukung. Maka dapat disimpulkan bahwa pelayanan merupakan suatu bentuk sistem, prosedur atau metode tertentu diberikan kepada orang lain, dengan harapan atau keinginan pelanggan dengan tingkat persepsi mereka. Faktor yang menyebabkan timbulnya pelayanan yaitu: adanya rasa cinta dan kasih sayang, adanya keyakinan bahwa berbuat baik kepada orang lain (3).

RSU Muhammadiyah Sumut selalu berusaha menciptakan manusia yang bersedia mengorbankan apa yang ada padanya sesuai kemampuaanya, diwujudkan menjadi layanan dan pengorbanan dalam batas ajaran agama, norma, sopan santun, dan kesusilaan yang hidup dalam masyarakat. Kepada semua karyawan khususnya petugas ruang rawat inap ditanamkan sikap peduli kepada sesama, dan memberikan pelayanan kepada pasien dan keluarga secara komprehensif tanpa membedakan agama, suku, dan status sosial. Semua harus mendapatkan pelayanan dan perawatan yang adil serta bermutu sehingga mereka tetap memilih loyal dengan rumah sakit. Dari hasil observasi juga ditemukan petugas membantu pasien tanpa memandang agama, suku dan status sosial kaya atau miskin, tidak pernah menunjukkan rasa jijik meskipun luka gangren pasien karena sakit gula tidak 
enak atau bau, petugas juga selalu memandikan pasien setiap pagi bagi yang perlu bantuan dan mengganti alat tenun pasien setiap hari dan jika kotor. Menurut asumsi peneliti, yang membedakan RSU Muhammadiyah Sumatera Utara dengan RS lainnya adalah menanamkan visi RS kepada seluruh karyawan yaitu menjadi rumah sakit islam yang unggul, professional, terpercaya di Sumatera Utara pada Tahun 2030 dengan berasaskan pada motto RS yakni beramal dengan ilmu dan kasih sayang untuk kesehatan anda.

Bila jasa/layanan yang diterima (perceived service) sesuai dengan yang diharapkan, maka kualitas jasa/layanan yang dipersepsikan baik dan memuaskan. Jika jasa yang diterima melampaui harapan pelanggan, maka kualitas jasa dipersepsikan sebagai kualitas yang ideal. Sebaliknya bila jasa/ layanan yang diterima lebih rendah dari pada diharapkan, maka kualitas/layanan akan dipersepsikan buruk. Pelayanan yang baik merupakan hak penuh masyarakat yang harus dijawab dengan kewajiban kita bersama untuk memberikan pelayanan yang prima dan membantu program pemerintah untuk menjamin kesehatan seluruh masyarakat. Kualitas pelayanan berdasarkan assurance di Unit Rawat Jalan RSU Muhammadiyah sudah baik. Hal ini dapat dilihat dari jenis spesialisasi yang ada di rumah sakit tipe D sudah terpenuhi yaitu 4 pelayanan dasar (Poli Obgyn, Poli Anak, Poli Penyakit Dalam dan Poli Bedah). Dokter spesialis yang ada juga masih mencukupi sesuai kebutuhan atau kunjungan pasien. Dokter spesialis obgyn berjumlah 3 orang, spesialis anak 1 orang, spesialis penyakit dalam 2 orang dan spesialis bedah 1 orang). Selain poli spesialis dasar rumah sakit juga mempunyai dokter spesialis lainnya seperti dokter spesialis mata, dokter speialis kulit dan kelamin.

\section{KESIMPULAN DAN SARAN}

Kesimpulan diperoleh bahwa ada hubungan tanglibility, reliability, responsiveness, assurance, empathy berhubungan dengan kepuasan pasien rawat jalan peserta JKN di RSU Muhammadiyah Sumatera Utara. Bagi pihak Rumah Sakit untuk menjaga loyalitas pelanggan dengan meningkatkan mutu pelayanan dan melengkapi sarana prasrana yang masih kurang seperti pemeriksaan laboratorium yang lengkap dan pemeriksaan radiologi, sehingga kepuasan pasien terpenuhi. Bertahannya pelanggan rumah sakit memiliki peran penting untuk mempertahankan keuangan dan kelangsungan hidup perusahaan.

\section{DAFTAR PUSTAKA}


1. Indonesia R. Undang-Undang No. 44 Tentang Rumah Sakit Tahun 2009. 2009;No. 44.

2. Istiqna N. Harapan Dan Kenyataan Pasien Jkn Terhadap Pelayanan Rawat Jalan Rumah Sakit Unhas Comparative Analysis Of Hope And Services Received By Patient Jkn Toward Outpatient Service Quality Of Unhas Hospital. J MKMI. 2015.

3. Tjiptono F. Pemasaran Jasa- Prinsip, penerapan dan penelitian. Yogyakarta: Andi offset; 2014.

4. Kepres. UU RI no 36 tahun 2009. Tentang Kesehatan. In 2013.

5. Farianita R. Faktor-Faktor Yang Berhubungan Dengan Kepuasan Peserta BPJS Terhadap Pelayanan Instalasi Rawat Jalan Di Rumah Sakit TK. III Bhakti Wira Tamtama Semarang. Universitas Negeri Semarang; 2015.

6. Keputusan Ketua Dewan Jaminan Sosial Nasional. Evaluasi dewan jaminan sosial nasional. Tentang Pedoman Monitoring dan Evaluasi Program Jaminan Kesehatan. 2014.

7. Aditama T. Manajemen Administrasi Rumah Sakit. Edisi kedua. Jakarta: UI Press. 2010.

8. Peraturan Presiden. Pepres RI No. 72 Tahun 2012 Tentang Sistem Kesehatan Nasional. 2012.

9. UU No 40 Tahun 2004 . Available from: http://www.pdpersi.co.id/peraturan/uu/uu402004.pdf

10. Mentri P. Peraturan Mentri Kesehatan RI no 71 tahun 20 Tentang Pelayanan Kesehatan Pada Jaminan Kesehatan Nasional. 2013.

11. Indriani A. Hubungan Mutu Pelayanan Kesehatan Dengan Kepuasan Pasien Diruangan Poli Umum Puskesmas Bukittinggi. 2017.

12. Hazfiarini D. Indeks Kepuasan Pasien BPJS Kesehatan Terhadap Pelayanan Rumah Sakit Mata Masyarakat Jawa Timur. J Adm Kesehat Indones. 2016.

13. Muhammad A, Umboh JML, Tucunan AAT. Hubungan antara Kualitas Pelayanan Kesehatan Rawat Jalan dengan Tingkat Kepuasan Pasien Peserta Jaminan Kesehatan Nasional di Puskesmas Siko Ternate. Tumou Tou. 2015.

14. Hamid AZ, Tucunan AAT, Mandagi CKF, Kesehatan F, Universitas M, Ratulangi $S$, et al. SAKIT TINGKAT IV LANUD SAM RATULANGI Undang-Undang Nomor 36 Tahun 2009 tentang kesehatan menjelaskan bahwa kesehatan adalah keadaan setiap orang yang menunjukkan sehat baik secara fisik, mental, spiritual maupun sosial yang memungkinkan setiap orang unt. 2019.

15. Silalahi JY, Fitriani AD, Megawati M. Analisis Mutu Pelayanan Perawat Terhadap Kepuasan Pasien Rawat Inap Kelas lii Di Rumah Sakit Advent Medan. J Kesehat PERINTIS (Perintis's Heal Journal) 2019. 
16. Supartiningsih S. Kualitas Pelayanan Kepuasan Pasien Rumah Sakit. J Medicoeticolegal dan Manaj Rumah Sakit, 6 9-15, Januari 2017 [Internet]. 2017.

17. Rahmawati D. Analisis Pengaruh Kualitas Pelayanan Terhadap Kepuasan dan Loyalitas. Revital J IImu Namajemen, Vol 6, Nomor 1, Maret 2017.

18. Manengkei $B$. Hubungan antara mutu jasa pelayanan dengan kepuasan pasien di ruang rawat inap rsu gmim pancaran kasih manado. $\mathrm{E} J$ Heal 2016.

19. Hardi J. Analisis Tingkat Kepuasan Pasien Umum Dan Pasien Jamkesmas Terhadap Mutu Pelayanan Rawat Inap Di Rsud Pasaman Barat Tahun 2010.

20. Sewow RNJ, Rattu AJM, Porotuo J, Universitas P, Ratulangi S, Kesehatan F, et al. Hubungan Antara Mutu Pelayanan dengan Loyalitas Pasien di Poliklinik

21. Interna Rumah Sakit Gunung Maria. Pascasarjana. Fakultas Kesehatan Masyarakat Universitas Sam Ratulangi. 2016.

22. Pengukuran Tingkat kepuasan Pelanggan". Jakarta: Rineka. 1997.

23. Irawan. 10 Prinsip Kepuasan Pelanggan. Jakarta: Elex Media Komputindo. 2009.

24. Gerson RF. Mengukur Kepuasan Pelanggan, PPM, Jakarta. 2004.

25. Lupiyoadi. buku Lupiyoadi 2001 Manajemen Pemasaran.

26. Setiono BA. menteri kesehatan republik indonesia nomor: 129/Menkes/SK/II/2008. undang-undang. 2008.

27. Martinench A. permenkes RI no 56 tahun 2014. Pontif Univ Catol del Peru. 2014.

28. Notoadmodjo. Metodologi Penelitian Kesehatan. Jakarta: Rineka Cipta. 2010.

29. Sugiyono. Metode Penelitian Kuantitatif, Kualitatif, dan R\&D. 2017.

30. Ghozali. Aplikasi Analisis Multivariate dengan Program IBM SPSS 25. Badan Penerbit Universitas Diponegoro: Semarang. Badan Penerbit Universitas Diponegoro: Semarang; 2005.

31. Bayu Wicaksono \& Nasir Widha Styanto, Analisis Kepuasan Pelanggan pada Pelayanan Kesehatan dengan Menggunakan Metode Potential Gain in Customer Value (PGCV) dan Entropy Studi Kasus Rumah Sakit Mardi Waluyo Kota Bilitar. Malang: Universitas Brawijaya.

32. Warwuru, P.M. Faktor-Faktor yang Berhubungan dengan Loyalitas Pelanggan di Instalasi Rawat Jalan di RSUP Prof. Dr. R.D. Kandou Manado.2018.

33. Solichah Supartiningsih, Kualitas Pelayanan Kepuasan Pasien Rumah Sakit: Kasus pada Pasien Rawat Jalan Rumah Sakit Sarila Husada Sragen. JMMr;2017.

34. Mu'ah \& Masram. Loyalitas Pelanggan Tinjauan Aspek Kualitas Pelayanan dan Biaya Peralihan. Surabaya: Zifatama; 2014. 
35. Aminudin Muhammad, Hubungan Antara Kualitas Pelayanan Kesehatan Rawat Jalan dengan Tingkat Kepuasan Pasien Peserta Jaminan Kesehatan Nasional di Puskesmas Siko Ternate. Universitas Sam Ratulangi; 2015.

36. Mardikanto,O.,dkk. Analisis Kepuasan Pelanggan dengan Metoda SERVQUAL di Rumah Sakit Condong Catur Yogyakarta; 2016.

37. Hurriyati, Ratih. Bauran Pemasaran dan Loyalitas Konsumen. Bandung: Alfabeta; 2015.

38. Sri Siswati, Kualitas Pelayanan Kesehatan dengan Kepuasan Pasien BPJS di Unit Rawat Inap RSUD Kota Makassar. Makassa: Universitas Hasanuddin; 2015.

39. Pendrita Jennie Kristina, Tavip Dwi Wahyuni \& Wahidyanti Rahayu, Hubungan Antara Kualitas Pelayanan dengan Tingkat Kepuasan Pasien Rawat Jalan Pengguna BPJS di RSI G Kabupaten Malang. Malang: Universitas Tribhuwana Tunggadewi Malang; 2017. 